\section{Addition of Maleic Anhydride to Anethole}

IN a communication bearing this title, and when referring to our papers ${ }^{1}$ on the uncrystallizable compound (m.p. $311-312^{\circ}$ ) formed during the course of the reaction which takes place between anethole and maleic anhydride, Bruckner and Kováss ${ }^{2}$ state that we have not recognized that this compound was a heteropolymer. In a series of other reports on the same subject published later, the heteropolymer character of the compound was established and, furthermore, its molecular weight was determined ${ }^{3}$ with the help of the cis-hexahydro-para-aminobenzoic acid lactam $^{4}$. The product which is obtained first under Bruckner's working conditions and our own, when refluxed with chloroform, yields two compounds, one of them soluble (m.p. $245^{\circ}$ decomp.), with a molecular weight equal to 738 (theoretical for $3: 3 \cdot 735$ ), and the other insoluble (m.p. $310^{\circ}$ de-<smiles>COC1=CC2CC(C)CC3(C=CC(OC)CC23)C1C(=O)O</smiles>

I

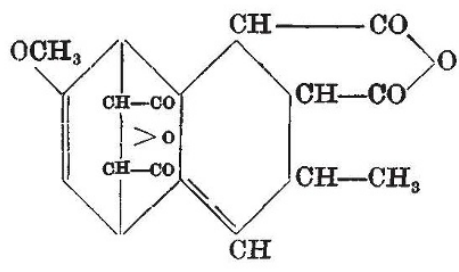

IJ<smiles>COOC(=O)C1Cc2cc(OC)ccc2CC1C</smiles>

III

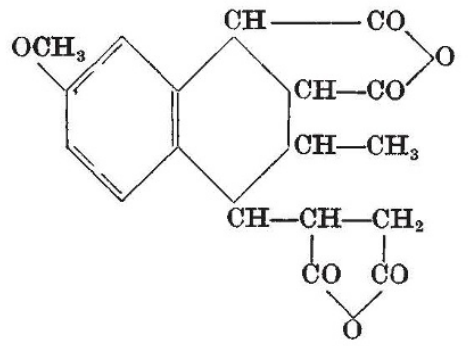

IV

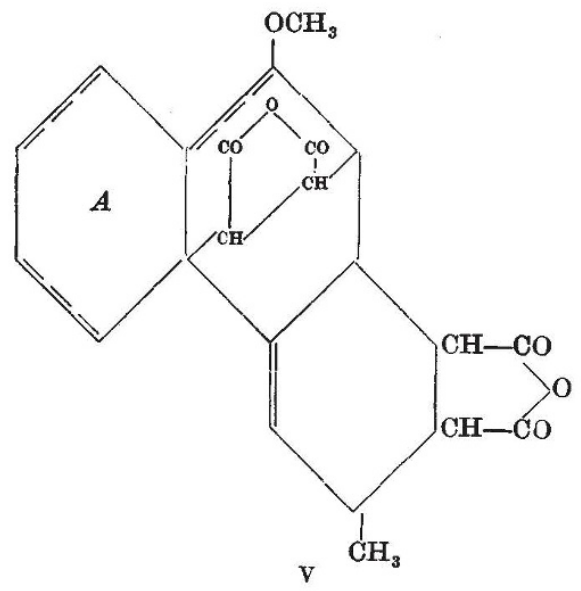

Concerning the structure of the compound formed, Bruckner considers that, from the point of view of diene synthesis, anethole behaves as a conjugated tetraene which would react successively as shown by I and II. Though we do not deny this possibility, we have directed attention to the possibility that the reaction takes place in the form indicated in III and IV, where the second molecule of maleic anhydride would react, following a process of substitution addition already mentioned by Adler ${ }^{8}$ as coincident with the diene synthesis.

The ultra-violet absorption spectra of these compounds are of the same type as that found for tetraline. When heated with selenium to $220^{\circ}$, characterization of the corresponding methyl-oxydicarboxylic acids, formed through loss of the second maleic anhydride molecule, is accomplished. With Bruckner's structure this may evidently take place due to the tendency of the nucleus to become aromatic ; with our own, through elimination of the lateral chains, in this case of succinic acid, a process usually accompanying the hydrogenation reactions. On the other hand, in the case of 1-4metoxypropenylnaphthalene it would be necessary to make allowance, following Bruckner, for the entrance of a second molecule as shown in V, and furthermore for the possibility of a new molecule adding itself to the conjugation in $A$; but we have found no compounds in the ratio of $1: 3$.

We are studying now the possibility of a reaction of substitution addition with the allylic isomers of these diene compounds which, taking place in these cases with transposition", gives rise to a conjugation capable of reacting, in the form of a diene synthesis, and producing compounds showing a structure which can be compared to that of those under considera. tion. The results and details of these investigations will

comp.), with a molecular weight equal to 1,010 (theoretical for $4: 4 \cdot 980$ ).

Bruckner and Kováss refer to the structure of the erystalline compound (m.p. $241^{\circ}$ ) formed by one mole of anethole and two moles of maleic anhydride, obtained by Bruckner in small quantitiess, and which he now obtains with a 60 per cent yield when a small amount of dimethylaniline is added.

We have found a crystalline compound (m.p. 232 $)$ in this ratio of $1: 2$ with a yield of 30 per cent, when the condensation is carried out in the presence of hydroquinone, which acts as an inhibiting agent towards polymerization ${ }^{3}$; and, moreover, we have characterized erystalline products with the same molar ratio in the condensation of maleic anhydride with o-metoxypropenylbenzene (m.p. $\left.241^{\circ}\right)^{8}$ and 1-4-metoxypropenylnaphthalene (m.p. 256-257 $)^{\circ}$. be published elsewhere.

\section{LoRa-Tamayo}

Department of Organic Chemistry,

"Alonso Barba" Institute of Chemistry, Madrid.

'Lora-Tamayo, M., and Ayestarán, D., Anal. Fis. Quim., 36, 44 $(1940) ; 37,392(1941)$.

${ }^{2}$ Bruckner and Kovács, Nature, 161, 650 (1948) (1943). 'Lora-Tamayo, M., and González, A., Anal. Fis. Quim., 89, 525
(1943).

${ }^{5}$ Bruckner, Ber., 75, 2035 (1942).

' Lora-Tamayo, M., and Martín Panizo, F., Anal. Fis. Quim., 40, 401 (1944).

'Lora-Tamayo, M., Martín Panizo, F., and Viguera, J., Anal. Fis. Quím., 41, 1325 (1945).

Adler and Cow, Ber., 76, 40 (1943).

- Adler, loc. cit.; Lora-Tamayo, M., and Larraz, M. C., Anal. Fis. Qutm., 44, 223 (1948)
${ }^{3}$ Lora-Tamayo, M., and Inflesta, J. L., Anal. Fis. Quim., 89, 634 